\title{
Actuarial Modeling of Life Insurance Using Decrement Models ${ }^{1}$
}

\author{
IVETA DIRGOVA LUPTAKOVA AND MARIA BILIKOVA
}

\begin{abstract}
The aim of this paper is to elucidate decrement models and their use in actuarial calculations in life insurance. The first part deals with the most often used decrement model, the mortality table. The second part gives an example based on a simple model to illustrate the creation of a multi-valued decrement table using the data from the single-value tables for a group of decrements and their use in insurance mathematical calculations.
\end{abstract}

General Terms: life insurance, decrement models

Additional Key Words and Phrases: mortality tables, actuarial calculations, multiple-state and multipledecrement models, construction of decrement tables.

\section{INTRODUCTION}

Actuarial practice confirms that its mathematical base is widely applicable in life insurance. Accordingly actuaries have developed a large range of models and varieties of methods and techniques in order to carry out so-called actuarial calculations. One of the most important reasons for actuarial modeling is so as to introduce reliable methods for the practical pricing of insurance contracts, i.e. for the calculation of the premium, which the insured life should pay the insurer, so that the latter will pay her or her next-of-kin the insured amount on the occurrence of the insured event. Another actuarial calculation is the valuation of an insurance contract, i.e. the determination of its value during the lifetime of the contract, the so-called insurance reserve, for which special requirements apply with regard how the insurer can invest the assets backing it and which forms the base for assessing the solvency of the insurer, i.e. its ability to meet its liabilities now and in the future. The paper deals only with the calculation of the value of an insurance contract, the reader can find out more about insurance reserves from for example [3] and [6].

\footnotetext{
${ }^{1}$ The paper arose in the context of the VEGA project VEGA no. 1/0542/13 Risk management and the actuarial function in life insurance.
} 


\subsection{The basic types of models for actuarial calculations}

We can subdivide actuarial calculation models into types according to various criteria. If we look at this from the point of view of the moments of time in which we make use of the available data, we get a division into discrete and continuous models. Whilst continuous models permit the use in calculations of derivatives and integrals and so from a mathematical perspective are elegant, for practical use discrete approaches are preferable, which we will show in the concrete examples.

Another division of the mathematical models for actuarial calculations is into deterministic and stochastic models. Deterministic models only make use for calculations of basic probability theory and are considered as the classical methods derived from two basic principles, the equivalence principle and the principle of an unreal set. Typical here is the use of the so-called commutation functions. The authors deal with this in detail in [5], and it will not be covered here.

When using the stochastic approach for actuarial calculations there are two different roads we can go along for modeling purposes, namely:

- modeling the future lifetime of the insured as a random variable,

- multiple-state modeling, where we follow the movement of the insured between the individual states of the system.

Any division of actuarial calculations would not be complete without the mention of the discounted cash-flow method, characterized in for example [4], which is more and more used for determining the premium in life insurance (in the profit-testing method), but also for calculating reserves (as the discounted value of the future cash-flows generated by the insurance contract).

\subsection{The mortality table}

The mortality table is a tool which in a practical way represents a model of mortality and belongs to the basic mathematical toolbox in life insurance. Most often used in life insurance are complete mortality tables, which contain separate figures for each integer age $x \in\{0,1,2, \ldots, \omega\}$, where $\omega$ is the assumed maximum age, which someone may attain.

The given description of a table is not universal. The separate columns of a mortality table give the values (in accordance with [5]):

$l_{x} \quad-$ the number of individuals surviving to age $x$. 
The finite series $\left\{l_{x}\right\}_{0}^{\omega}$ je non-increasing and is called the life table or survival function.

$d_{x} \quad-$ the number of individuals who dies at age $x$, where we have $d_{x}=l_{x}-l_{x+1}$.

$q_{x}$ - the mortality rate, that is the probability an individual alive at age $x$ dies before attaining age $x+1$. Clearly $q_{x}=\frac{l_{x}-l_{x+1}}{l_{x}}$.

$p_{x}-$ the survival rate, that is the probability an individual alive at age $x$ survives to age $x+1$. We have $p_{x}=1-q_{x}$.

${ }_{t} p_{x}-$ the probability an individual alive at age $x$ survives to age $x+t$.

${ }_{t} q_{x}-$ the probability an individual alive at age $x$ does not survive to age $x+t$.

In the case where the survival function $l_{x}$ is continuous we can define the intensity of mortality for a life aged $x$ (in accordance with [2]):

$$
\mu_{x}=-\frac{1}{l_{x}} \cdot \frac{\mathrm{d}\left(l_{x}\right)}{\mathrm{d} x}=\lim _{t \rightarrow 0^{+}} \frac{q_{x}}{t}
$$

as the "instantaneous rate" of dying, thus a value which is independent of the time $t$.

\subsection{The basic principles of multiple-state and decrement models}

A multiple-state model is a closed system, containing a finite number of states, in one of which the process we are following (for example the lifetime of a person) can be at any time. The simplest such model is the two-state model, which we will now deal with.

The two-state alive - dead model

In this case the individual can be in one of two states, namely the starting state (1) alive and in the absorbing (no exit from it is possible) state (2) - dead. This model is shown in Figure 1:

Figure 1. The two-state alive - dead model

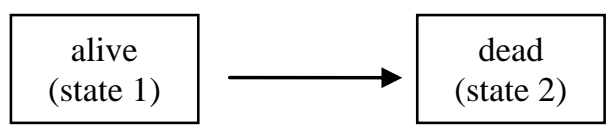

We can define the conditional transition probability ${ }_{t} p_{x}^{i j}$ between the states $i$ and $j$ and between the ages $x$ and $x+t$ (for example in accordance with [1]): 


$$
{ }_{t} p_{x}^{i j}=P[\text { life is in state } j \text { at age } x+t \mid \text { life is in state } i \text { at age } x] \text {; for } i, j=1,2 \text {. }
$$

The relationships between these probabilities and the actuarial notation for the probabilities relating to death and survival are (see for example [3]):

$$
{ }_{t} p_{x}={ }_{t} p_{x}^{11} ; \quad{ }_{t} q_{x}={ }_{t} p_{x}^{12} ; \quad{ }_{\mathrm{t}} q_{x}={ }_{t} p_{x}^{11} \cdot p_{x+t}^{12},
$$

where ${ }_{\mathrm{t} \mid} q_{x}$ is the probability that the life aged $x$ dies between age $x+t$ and age $x+t+1$.

Multiple-state models allow more than one transition between the states of the process, some of which are reversible (the life can after some time in the new state return to the previous state), others are irreversible. In the process there can also exist absorbing states, from which it is not possible to exit.

A special case of the multiple-state model is the multiple-decrement model, in which there is one base state, using denoted as $(0)$, most often representing the fact that the life is alive or active. From this state it is only possible to leave to one of $r$ absorbing states, called decrements $(k)$, where $k \in\{1,2, \ldots, r\}$. In the actuarial literature (e.g. [7]) the probabilities relating to multiple-decrement models are given the symbols:

${ }_{t}(a p)_{x}={ }_{t} p_{x}^{00} \quad-\quad$ the probability a life aged $x$ stays $t$ years in the base state $(0)$, ${ }_{t}(a q)_{x}^{k}={ }_{t} p_{x}^{0 k} \quad-\quad$ the probability a life aged $x$ at some future time $t$ leaves the base state due to decrement $k$, for $k \in\{1,2, \ldots, r\}$,

$(a \mu)_{x}^{k}=\lim _{t \rightarrow 0^{+}} \frac{p_{x}^{0 k}}{t} \quad-\quad$ the transition intensity for a life aged $x$ due to decrement $k$, $(a \mu)_{x}=\sum_{k=1}^{r}(a \mu)_{x}^{k} \quad-\quad$ represents the so-called total decrement intensity for a life aged $x$, which depends on all of the $r$ decrement intensities.

When in the first two expressions $t=1$, it is left out when they are written down. These are then the so-called survival rate in the base state for a life aged $x$ and the rate of decrement due to decrement $k$ for a life aged $x$, respectively. 


\section{THE USE OF MULTIPLE-DECREMENT MODELS FOR PREMIUM CALCULATION}

\subsection{The mortality table as a single-decrement model}

For a simple model we show the creation of a mortality table from observed data.

Let us assume that we follow a group of students on a two year post-high school course. At the start of the course they are aged 18 and we observe the following:

- $\quad$ the number of students at the start of the first year was 550,

- $\quad$ during the course of the first year 5 students died,

- $\quad$ during the course of the second year 7 students died.

Using these data we can construct part of a mortality table.

In the model shown we have the base state $(0-$ alive $)$ and one possibility of decrement to state $(1-$ dead). This is then a single-decrement model, as illustrated in Figure 2.

Figure 2. Single-decrement model of a post-high school course

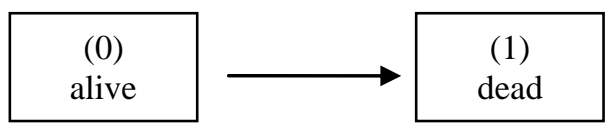

In the mortality table we show the following observed quantities:

$x \quad-\quad$ represents the age of the students on the course, $x=18,19,20$,

$l_{x} \quad-\quad$ represents the number of students aged $x, l_{18}=550 ; l_{19}=545 ; l_{20}=538$,

$d_{x} \quad-\quad$ the number of students who in the given year died, $d_{18}=5 ; d_{19}=7$.

On the basis of the above we can calculate the probabilities for each age $x$ and thus create a single-decrement table (Table 1). For example for age 18 we have:

$$
q_{18}=\frac{l_{18}-l_{19}}{l_{18}}=0,009 \quad, \quad p_{18}=\frac{l_{19}}{l_{18}}=0,991
$$

Table 1. Mortality table for the post-high school course

\begin{tabular}{|c|c|c|c|c|}
\hline $\boldsymbol{x}$ & $l_{x}$ & $d_{x}$ & $q_{x}$ & $p_{x}$ \\
\hline 18 & 550 & 5 & 0,009 & 0,991 \\
\hline 19 & 545 & 7 & 0,013 & 0,987 \\
\hline 20 & 538 & \multicolumn{3}{|r}{} \\
\cline { 1 - 5 }
\end{tabular}


We will illustrate the use of this table with a simple example of a term assurance contract.

We will calculate the present value (denoted $\pi$ ) of a term assurance contract for a student on the course, who is now aged 18 and who insures herself for an amount of $€ 10,000$ payable, at the end of the year of death, to her next-of-kin if she dies during the course. We will ignore the insurer's expenses and assume that the insurer expects to earn a rate of interest of $2 \%$ on its assets. In solving the task we will use the standard actuarial notation (as given for example in [2]), where $v=(1,02)^{-1}$ is the discount factor.

$$
\begin{gathered}
\pi\left(A_{18, \overline{2} \mid}^{1}\right)=\left(q_{18} \cdot v+p_{18} \cdot q_{19} \cdot v^{2}\right) \cdot 10000 \\
\pi\left(A_{18, \overline{2} \mid}^{1}\right)=€ 212.06
\end{gathered}
$$

\subsection{Multiple-decrement model}

Given that a student can leave the course for reasons other than death, we will extend the previous model to include the following possibilities: voluntary withdrawal from the course and expulsion from the course due to poor results, where the various reasons can be stated as decrements. We therefore have three decrements:

- decrement (1) - death,

- decrement (2) - voluntary withdrawal from the course,

- $\quad$ decrement (3) - expulsion from the course due to poor results.

This situation is represented in Figure 3.

Figure 3. Three-decrement model of a post-high school course

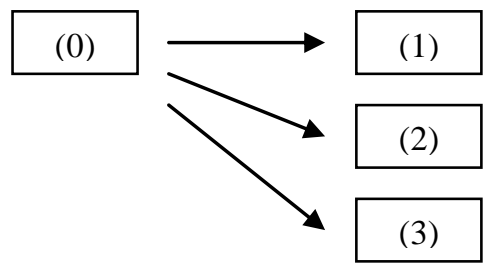

With regard to each decrement from the base state we can proceed:

a) independently $\quad-$ we obtain three (in general $r$ ) single decrement tables $\left\{S D T_{k}\right\}_{k=1}^{3}$, in which the decrement probability $q_{x}^{k}$ is usually referred to as the independent rate of decrement due to cause $k$, 
b) joint $\quad-$ we get the multiple-decrement table $(M D T)$, in which the decrement probability $(a q)_{x}^{k}$ is usually referred to as the dependent rate of decrement due to cause $k$.

We will use the following decrement rates (Table 2), where $q_{x}^{k}$ is the probability of a decrement of type $k$ in the appropriate $S D T_{k}$ for a life aged $x$, for $k=1,2,3$ and $x=18$, 19.

Table 2. Table of single-decrement rates for the post-high school course model

\begin{tabular}{|c|c|c|c|}
\hline $\boldsymbol{x}$ & $q_{x}^{1}$ & $q_{x}^{2}$ & $q_{x}^{3}$ \\
\hline 18 & 0,009 & 0,02 & 0,04 \\
\hline 19 & 0,013 & 0,015 & 0,046 \\
\hline 20 & \multicolumn{3}{|l}{} \\
\cline { 1 - 3 } & &
\end{tabular}

From the data shown in Table 2 we can construct a multiple-decrement table.

The decrement intensities in both the multiple-decrement model and the separate single-decrement models are independent of time and so are not influenced by the operation of the other decrements. This fact is captured in the following equation (see [7]) known as the associability condition for associating the multiple-decrement model with the system of single-decrement models:

$$
(a \mu)_{x}^{k}=\mu_{x}^{k} \text { for } k \in\{1,2, \ldots, r\}, x \in\langle 0, \omega) .
$$

If these equalities apply we then have that:

$$
{ }_{t}(a p)_{x}=\prod_{t} p_{x}^{k} \text { for } k \in\{1,2, \ldots, r\} .
$$

The dependent rates $(a q)_{x}^{k}$, and also the values $(a d)_{x}^{k}$, representing the number of lives, who exit from the base state due to decrement $k$ at age $x$, are usually calculated using approximations if the previously stated conditions apply.

If we assume that the survival function $l_{x}^{k}$ is linear in the single-decrement model $S D T_{k}$ for $k \in\{1,2, \ldots, r\}$ during each year of age $(x, x+1)$ we can prove the following relationships (see [2]): 


$$
\begin{array}{lr}
{ }_{t} p_{x} \mu_{x+t}^{k}=\text { constant }=q_{x}^{k} & \text { for } k, 0 \leq t \leq 1 \\
{ }_{t} q_{x}^{j}=t \cdot q_{x}^{j} & \text { for } j \neq k, 0 \leq t \leq 1 \\
{ }_{t} p_{x}^{j}=1-{ }_{t} q_{x}^{j}=1-t \cdot q_{x}^{j} &
\end{array}
$$

We can rewrite the equation for determining the dependent rate of decrement for decrement $k$ at age $x$ (see [7]):

$$
(a q)_{x}^{k}=\int_{0}^{1}{ }_{t}(a p)_{x} \cdot(a \mu)_{x+t}^{k} \cdot \mathrm{d} t
$$

using the relationships from the assumption of associability and assuming linearity of the survival functions as follows:

$$
\begin{aligned}
& (a q)_{x}^{k}=q_{x}^{k} \int_{0}^{1}\left(1-t \cdot q_{x}^{1}\right) \cdot\left(1-t \cdot q_{x}^{2}\right) \cdots\left(1-t \cdot q_{x}^{k-1}\right) \cdot\left(1-t \cdot q_{x}^{k+1}\right) \cdots\left(1-t \cdot q_{x}^{r}\right) \cdot \mathrm{d} t \\
& (a q)_{x}^{k}=q_{x}^{k} \int_{0}^{1}\left(1-t \cdot \sum_{j \neq k} q_{x}^{j}+t^{2} \cdot \sum_{i \neq j \neq k} q_{x}^{i} \cdot q_{x}^{j}-\cdots\right) \cdot \mathrm{d} t
\end{aligned}
$$

By integrating we then obtain:

$$
(a q)_{x}^{k}=q_{x}^{k}\left(1-\frac{1}{2} \sum_{j \neq k} q_{x}^{j}+\frac{1}{3} \sum_{i \neq j \neq k} q_{x}^{i} \cdot q_{x}^{j}-\cdots\right) .
$$

If $r=3$, we get the following set of equations:

$$
\begin{aligned}
& (a q)_{x}^{1}=q_{x}^{1} \cdot\left(1-\frac{1}{2}\left(q_{x}^{2}+q_{x}^{3}\right)+\frac{1}{3} q_{x}^{2} \cdot q_{x}^{3}\right) \\
& (a q)_{x}^{2}=q_{x}^{2} \cdot\left(1-\frac{1}{2}\left(q_{x}^{1}+q_{x}^{3}\right)+\frac{1}{3} q_{x}^{1} \cdot q_{x}^{3}\right) \\
& (a q)_{x}^{3}=q_{x}^{3} \cdot\left(1-\frac{1}{2}\left(q_{x}^{1}+q_{x}^{2}\right)+\frac{1}{3} q_{x}^{1} \cdot q_{x}^{2}\right)
\end{aligned}
$$

In this way we obtain all the dependent decrement rates in the multiple-decrement model from the known associated single-decrement rates. The values in a multipledecrement table are usually expressed as integers with a sufficiently large radix.

Thus on the basis of the assumption of linearity of each decrement between integer ages we can estimate the values $(a q)_{x}^{k}$ - the probabilities that a life aged $x$ leaves the base state due to decrement $k$, for $k=1,2,3$ and $x=18,19$ 
For example for $(a q)_{18}^{1}$ we obtain the value:

$$
(a q)_{18}^{1}=q_{18}^{1} \cdot\left[1-\frac{1}{2}\left(q_{18}^{2}+q_{18}^{3}\right)+\frac{1}{3}\left(q_{18}^{2} \cdot q_{18}^{3}\right)\right]=0,0087
$$

Similarly we can determine all the necessary values for $(a q)_{x}^{k}$ and set them out in table 3 .

Table 3. Table of three-decrement rates for the post-high school course model

\begin{tabular}{|c|c|c|c|}
\hline$x$ & $(a q)_{x}^{1}$ & $(a q)_{x}^{2}$ & $(a q)_{x}^{3}$ \\
\hline 18 & 0,0087 & 0,0195 & 0,0394 \\
\hline 19 & 0,0126 & 0,0146 & 0,0454 \\
\hline 20 & \multicolumn{3}{|l}{} \\
\cline { 1 - 2 } & &
\end{tabular}

Since we are interested in the values of $(a d)_{x}^{k}$, which directly give the number of students who leave the base state due to decrement $k$, we can calculate these using the relationship:

$$
(a d)_{x}^{k}=(a l)_{x} \cdot(a q)_{x}^{k}
$$

where $(a l)_{x}$ represents the number of lives aged $x$ who are in the base state $(0)$, i.e. are students of the two-year post-high school course aged $x$. When constructing tables we typically use a hypothetical group of students, in that we choose a suitable constant as the table's radix, for example $(a l)_{18}=10,000$.

The values calculated using the preceding equation specify the three-decrement table for the model of the two-year post-high school course with three possible modes of exit: death, voluntary withdrawal and expulsion (Table 4.).

Table 4. Three-decrement table for the model of the post-high school course

\begin{tabular}{|c|c|c|c|c|}
\hline$x$ & $(a l)_{x}$ & $(a d)_{x}^{1}$ & $(a d)_{x}^{2}$ & $(a d)_{x}^{3}$ \\
\hline 18 & 10,000 & 88 & 195 & 394 \\
\hline 19 & 9,323 & 118 & 136 & 423 \\
\hline 20 & 8,590 & \multicolumn{3}{|r}{} \\
\cline { 1 - 4 } & &
\end{tabular}

We will conclude by showing how, similarly to the single-decrement model, we can use this model in the case of a term assurance contract. 
We will calculate the present value of a term assurance contract for a student on the course, who is now aged 18 and who insures herself for an amount of $€ 10,000$ payable to her next-of-kin, at the end of the year of death, if she dies during the course (i.e. exit from the course due to decrement (1)). Again we will ignore the insurer's expenses and assume that the insurer expects to earn a rate of interest of $2 \%$ on its assets.

Similarly to the first example we obtain:

$$
\begin{gathered}
\pi=\left((a q)_{18}^{1} \cdot v+(a p)_{18} \cdot(a q)_{19}^{1} \cdot v^{2}\right) \cdot 10,000 \\
\pi=€ 198.21
\end{gathered}
$$

In both examples the present values we have calculated represent the single net premium which the student needs to pay at the start of the first year of the course, if she would like her next-of-kin to receive the insured amount at the end of the year in which she died.

\section{SUMMARY}

In this paper the authors did not set out to present the complicated theory of multiple-decrement models as a special case of multiple-state models in discrete or continuous time, Markov or non-Markov, but using simple situations to present the basic possibilities, which these models open up in actuarial calculations.

The most common example of the use of multiple-decrement models in practice is for the modeling of actuarial calculations for pension schemes (in Slovakia they can be used by the Supplementary Pension Insurers), where paying members of the scheme can exit from it due to decrements such as: normal age retirement, ill-health retirement, withdrawal from the scheme due for example to change of employment and death.

Actuaries working in insurance companies can use the paper as an incentive to delve into the detailed actuarial literature relating to the mentioned methods and then use them in their day-to-day work.

\section{REFERENCES}

[1] BILÍKOVÁ, M., LUPTÁKOVÁ, I.: Použitie viacstavových modelov v aktuárskych výpočtoch pri poisteni $o s \hat{b}$. (The use of multiple-state models in actuarial calculations for life insurance) Ekonomika a informatika no. 1/2005, Bratislava EU, 2005 ISSN 1336-3514.

[2] BILÍKOVÁ, M. 2003. Spojité metódy v poistnej matematike. (Continuous methods in insurance mathematics) Bratislava: EKONÓM Publishers, 2003 
[3] CIPRA, T. 1999. Pojistná matematika teoria a praxe. (Insurance mathematics in theory and practice) Praha: Ekopress, 1999.

[4] SAKÁlOVÁ, K. 2001. Oceňovanie produktov v životnom poistení. (Product pricing in life insurance) Bratislava: EKONÓM Publishers, 2001.

[5] SEKEROVÁ, V. - BILÍKOVÁ, M. 2007. Poistná matematika. (Insurance mathematics) Bratislava: EKONÓM Publishers, 2007.

[6] ŠPIRKOVÁ, J. - URBANÍKOVÁ, M. 2012. Aktuárska matematika - životné poistenie. (Actuarial mathematics - life insurance) Bratislava: IuraEdition, 2012.

[7] Module D "Actuarial Mathematics" - study material. Actuarial Education Service. Oxford 1993.

Iveta Dirgová Luptáková,

Department of Applied Informatics and Mathematics,

Faculty of Natural Science,

University of SS. Cyril and Methodius,

Nám. J. Herdu 2, 91701 Trnava, Slovakia

tel. 033/55 65 372, e-mail: iveta.dirgova@ucm.sk

Mária Bilíková,

Department of Mathematics and Actuarial Science,

Faculty of Economic Informatics,

University of Economics in Bratislava,

Dolnozemská cesta 1/b, 85235 Bratislava, Slovakia

tel. 02/672 95 842, e-mail: maria.bilikova@euba.sk 